\title{
Prevalence of iron deficiency and iron deficiency anaemia among nursing students of Bilaspur Chhattisgarh
}

\author{
Saha $\mathbf{J}^{1}$, Sarkar $\mathbf{D}^{2}$ \\ ${ }^{1}$ Dr Jayanta Saha, Assistant Professor, Department of Physiology, Chhattisgarh Institute of Medical Sciences, Bilaspur, \\ ${ }^{2}$ Dr Derbashree Sarkar, Associate Professor, Department of Physiology, Pt. Jawaharlal Nehru, Memorial medical College \\ Raipur, CG, India
}

Address for Correspondence : Jayanta Saha, Assistant Professor, Department of Physiology, Chhattisgarh Institute of Medical Sciences, Bilaspur (C.G), Email ID: jayanta_sahain@yahoo.co.in

\begin{abstract}
Background and Aim: The most widespread nutritional problem is iron deficiency affecting over two billion people. It is particularly common disorder among infants, preschool children, young women and older people but it can occur at ages and in any region. A high demand for iron during rapid growth, pregnancy and lactation, accompanied by dietary deficiency in children and young women, can lead to iron deficiency anaemia. Materials and Methods: The present study carried out at Department of Biochemistry, Chhattisgarh Institute of Medical Sciences, Bilaspur (CG). A total 112 female students participated in this cross sectional study was age between 18-25 years. Complete blood cell count and Serum iron, Ferritin, total iron binding capacity were used to assess the status of iron deficiency and iron deficiency anaemia. Results: We found significant $(\mathrm{P}<0.001)$ decrease level of Serum Iron and Ferritin and significant $(\mathrm{P}<0.001)$ increased level of TIBC in ID as well as IDA as compared to Normal. In this study, the prevalence rates of ID and IDA in female university students aged 18-25 years were 55.35\% and 10.7\%, respectively. Conclusion: The results of this study indicate that iron supplementation is required for the target group. Finally, nutrition education and intervention program should address ID with a focus on both the dietary quantity and the quality of the micronutrient composition. All of these interventions must be monitored for effectiveness.
\end{abstract}

Key words: Iron Deficiency Anemia, Iron Deficiency, Nursing Students

\section{Introduction}

Iron deficiency (ID) is the most prevalent nutritional disorder in the world [1] and Iron deficiency is the most frequent cause of anemia [2-4]. It is estimated that around 2.15 billion individuals suffer from iron deficiency anemia [5]. It is particularly common disorder among infants, pre-school children's, young women and older people but it can occur at ages and in any region. A high demand for iron during rapid growth, pregnancy and lactation, accompanied by dietary deficiencies and menstrual blood loss, are the most common causes of iron deficiency in children and young women. Iron deficiency is considered one of the ten global risk factors in terms of its disease burden [6].

Anaemia is associated with low work capacity, a poor

Manuscript received: $1^{\text {st }}$ July 2015

Reviewed: $10^{\text {th }}$ July 2015

Author Corrected: $19^{\text {th }}$ July 2015

Accepted for Publication: $4^{\text {th }}$ Aug 2015 pregnancy outcome as well as lasting effects on learning and cognitive functions, attention behaviour, health and growth $[7,8]$. The prevalence of ID and Iron deficiency anaemia IDA is higher in less developed countries as compared to developed countries. Although the diagnosis of ID is relative simple, it may go unnoticed for a long time due to its non specific clinical sign. The most common sign of ID includes paleness, anorexia, apathy, irritability, reduced attention span and psychomotor deficiencies. Adolescence is a critical stage in the life cycle, when the health of female is affected due to growth spurt, beginning of menstruation, poor intake of iron due to poor dietary habits and gender bias. Iron deficiency Anemia affects over $60 \%$ of the adolescent girls in India. Anemia in adolescent girls has far- reaching implication. The anaemic adolescent girls grow into adult women have low pregnancy weight babies [9]. In a recent review of 
the prevalence of iron deficiency anemia in the United States, $9 \%$ of toddlers and up to $11 \%$ of adolescent girls were iron deficient [10]. Although nutritional deficiencies of folate and vitamin B12, infectious diseases, such as the human immunodeficiency virus, hookworm, malaria and other chronic diseases, may account for anemia, according to the literature, more than $50 \%$ of cases of anemia in young children and pregnant women in developing countries are related to iron deficiencies [11-12]. In the World Health Organization (WHO)/World Bank rankings, IDA is the third leading cause of disability-adjusted life years lost for females aged 15-44 years [12-13]. It is the only nutrient deficiency which is also significantly prevalent in virtually all industrialized nations. In addition, there are no current global figures for iron deficiency, but using anemia as an indirect indicator it can be estimated that most female preschool children and pregnant women in non-industrialized countries, and at least 30 to $40 \%$ in industrialized countries, are iron deficient [14].

Since female adolescents and adults are among the population groups who are most affected by it, the present study was conducted to determine the prevalence of ID and IDA among apparently healthy female nursing students.

\section{Materials and Methods}

A total 112 healthy female students age between 18-25 years were selected for the study. Three students having history of sickle cell anaemia were excluded from the study. The study was carried out with due approval of the institutional human ethical committee, written informed consent was obtained from all subjects before the study. Iron deficiency (ID) was defined as ferritin $<15 \mathrm{ng} / \mathrm{ml}$ with hemoglobin $\geq 12.0 \mathrm{~g} / \mathrm{dl}$ an iron deficiency anemia (IDA) as ferritin $<15 \mathrm{ng} / \mathrm{ml}$ with hemoglobin <12 g/dl [15]. A detailed physical examination was conducted on all participants. Height and weight of students were measured and body mass index (BMI) was calculated as body weight in kilograms divided by square of height in meters \{body weight $(\mathrm{Kg}) /$ height $\left.\left(\mathrm{m}^{2}\right)\right\}$. Five $\mathrm{ml}$ of blood samples were obtained from each participant. Blood sample was used for haematological and biochemical tests. Complete hemogram was analysed by mythic 18 cell counter make Orphee SA, France, the Serum iron and Total iron binding capacity (TIBC) levels were measured calorimetrically by commercially available kit (Coral Diagnostic India) by and estimation of serum Ferritin was done by Radioimmunoassay Assay. (Kit Make DPC, Diagnostic USA).

Statistical Analysis: The statistical analysis was performed using the Statistical Package for Social Science version 16 (SPSS Inc, Chicago, IL USA). The student's t test for continuous variable was used to compare the difference between the groups. A p- value of 0.05 was considered to be statistically significan

\section{Result}

A total 112 students were included in this study. Their ages ranged between 18 to $25 \mathrm{yrs}$, with a mean age of 19.8 yrs. Subjects were divided into three groups as group first Normal, group second ID (Iron deficiency) and Group third IDA (Iron deficiency anemia). The criteria for the division was $\mathrm{Hb} \geq 12.0 \mathrm{~g} / \mathrm{dl}$ and serum Ferritin $\geq 15.0 \mathrm{ng} / \mathrm{ml}$ (group 1), Group $2 \mathrm{Hb} \geq 12.0 \mathrm{~g} / \mathrm{dl}$ and Ferritin $<15.0 \mathrm{ng} / \mathrm{ml}$ and Group $3 \mathrm{Hb} \leq 12.0 \mathrm{~g} / \mathrm{dl}$ and Ferritin $<15.0 \mathrm{ng} / \mathrm{ml}$. There were thirty eight, sixty two and 12 subjects in group $1,2 \& 3$ respectively.

Table 1:- Haematological and iron indices as mean and standard deviation (SD) of all the participants $(\mathbf{n}=112)$

\begin{tabular}{|l|l|l|}
\hline Parameters & Mean & SD \\
\hline TRBC ( millions/cumm) & 4.77 & .71 \\
\hline Hct $(\%)$ & 37.93 & 5.71 \\
\hline Hb $(\mathbf{g} / \mathbf{d l})$ & 12.26 & 1.34 \\
\hline MCV(fl) & 79.07 & 11.73 \\
\hline MCH(pg) & 24.98 & 6.76 \\
\hline MCHC $(\%)$ & 31.09 & 6.35 \\
\hline Ferritin $(\mathbf{n g} / \mathbf{m l})$ & 24.55 & 17.23 \\
\hline Serum Iron $(\boldsymbol{\mu g} / \mathbf{d l})$ & 69.95 & 21.22 \\
\hline TIBC $(\boldsymbol{\mu g} / \mathbf{d l})$ & 398.90 & 64.81 \\
\hline BMI $\left(\mathbf{k g} / \mathbf{m}^{2}\right)$ & 19.92 & 2.52 \\
\hline
\end{tabular}


The above table shows the mean and (SD) of TRBC (millions/cumm) $=4.77(0.71), \mathrm{Hct}(\%)=37.97(5.71), \mathrm{Hb}(\mathrm{g} / \mathrm{dl})$ $=12.26(1.34), \mathrm{MCV}(\mathrm{fl})=79.07(11.73), \mathrm{MCH}(\mathrm{pg})=24.98(6.76), \operatorname{MCHC}(\%)=31.09(6.35), \quad$ Ferritin $(\mathrm{ng} / \mathrm{ml})=24.55(17.23)$, $\operatorname{Serum} \operatorname{Iron}(\mu \mathrm{g} / \mathrm{dl})=69.95(21.22)$ and $\operatorname{TIBC}(\mu \mathrm{g} / \mathrm{dl})=398.90(64.81)$

Data of table no 1 shows the iron status of all the participants (Mean \pm SD). The prevalence of ID and IDA in this study was $55 \%, \& 11 \%$ respectively as shown in the pie chart 1 .

Table 2: comparative result haematological and iron indices as mean and standard deviation (SD) of three groups i.e. Normal , ID and IDA

\begin{tabular}{|c|c|c|c|}
\hline Parameters & $\begin{array}{l}\text { Group } 1 \\
(n=38)\end{array}$ & $\begin{array}{l}\text { Group } 2 \\
(n=62)\end{array}$ & $\begin{array}{l}\text { Group } 3 \\
(n=12)\end{array}$ \\
\hline TRBC( millions/cumm) & $5.12 \pm .58$ & $4.56 \pm .71$ & $4.72 \pm .69$ \\
\hline $\operatorname{Hct}(\%)$ & $42.36 \pm 4.95$ & $36.49 \pm 3.78$ & $31.38 \pm 6.48 *$ \\
\hline Hb (g/dl) & $12.70 \pm .60$ & $12.11 \pm .53$ & $08.65 \pm 1.65$ \\
\hline MCV(fl) & $82.71 \pm 7.10$ & $79.39 \pm 12.43$ & $65.92 \pm 4.03$ \\
\hline MCH(pg) & $26.57 \pm 9.05$ & $25.19 \pm 4.64$ & $18.88 \pm 4.03$ \\
\hline MCHC (\%) & $30.29 \pm 3.03$ & $31.09 \pm 8.84$ & $28.62 \pm 2.24$ \\
\hline Ferritin (ng/ml) & $37.65 \pm 26.54$ & $19.81 \pm 3.34$ & $8.81 \pm 2.67 *$ \\
\hline $\operatorname{Serum} \operatorname{Iron}(\mu \mathrm{g} / \mathrm{ml})$ & $80.25 \pm 15.29$ & $48.55 \pm .14$ & $26.58 \pm 6.96^{*}$ \\
\hline TIBC $(\mu \mathrm{g} / \mathrm{dl})$ & $340.26 \pm 43.81$ & $441.55 \pm 43.57$ & $462.42 \pm 77.27 *$ \\
\hline BMI $\left(\mathrm{kg} / \mathrm{m}^{2}\right)$ & $19.78 \pm 2.43$ & $19.66 \pm 2.51$ & $18.93 \pm 2.64^{\mathrm{NS}}$ \\
\hline
\end{tabular}

TRBC: Total Red blood cell count, Hb: Haemoglobin, HCT: hematocrit, MCV: mean Corpuscular Volume, MCH: mean corpuscular haemoglobin, MCHC: mean corpuscular haemoglobin concentrate, TIBC: total iron binding capacity, BMI: body mass index (* highly significant at $\mathrm{p}<0.001$, NS: not significant).

Table no 2 shows significant $(\mathrm{P}<0.001)$ decrease level of Serum Iron and Ferritin and significant $(\mathrm{P}<0.001)$ increased level of TIBC in ID as well as IDA as compared to Normal. We did not found any significant differences in BMI between ID, IDA as compared to normal.

The table data shows significant $(\mathrm{P}<0.001)$ decrease level of Serum Iron and Ferritin and significant $(\mathrm{P}<0.001)$ increased level of TIBC in ID as well as IDA as compared to Normal.

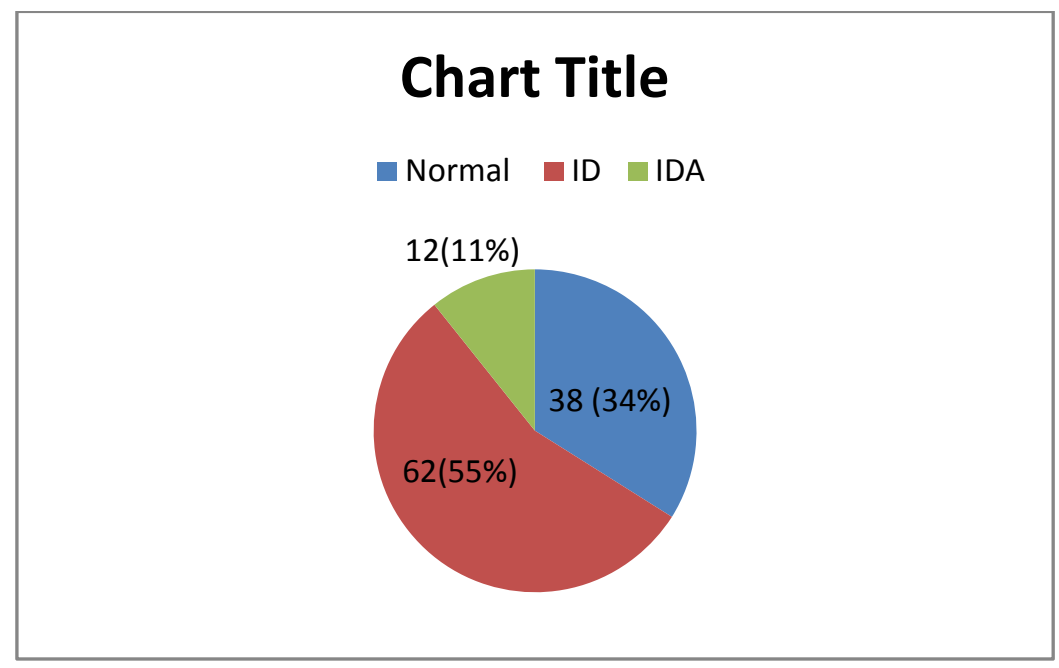

Pie chart 1 - The Prevalance of Iron deficiecny and Iron Deficiency Anemia among all participants. 


\section{Discussion}

Iron deficiency anemia is the most common nutritional deficiency worldwide. The negative consequences of IDA on the cognitive and physical development of children and on the work productivity of adults are of major concern [16]. ID usually develops in a sequential manner over a period of negative iron balance, such as periods of blood loss and / or prolonged iron -deficient diets, accelerated growth in children and adolescents as well as during pregnancy and lactation [17-18]. These staged include the iron -depletion phase, iron-deficient erythropoisis and IDA. IDA affects $43 \%$ of pre school children all over the world, especially in developing countries, where its prevalence rate is four times higher than in industrial countries [19]. Iron deficiency usually develops slowly and insidiously. Many patients have no specific complaints; others have vague symptoms of tiring easily, headache, irritability, or depression [20]. Probably the single most important clinical clue to anemia is the symptom of chronic fatigue [21]. In one study in India $20 \%$ of female college students were found to be anemic, Latent iron deficiency /ID (low serum Ferritin, <15.0 ng/ml, with normal Hb, $12.0 \mathrm{~g} / \mathrm{dl}$ or more) was found amongst 19 (27.5\%) subjects [22]. In this study the prevalence of ID 55\% was higher than that of IDA $11 \%$. Subjects with ID are likely to develop IDA over a period of time and should receive iron therapy to correct their ID and prevent the development of IDA. Although $15.0 \mathrm{ng} / \mathrm{ml}$ of Ferritin level is taken as cut off level for diagnosis of ID, there are reports to suggest that even at higher levels of ferritin, there is evidence of iron deficient erythropoisis [23-25]. The results of this study indicate that iron supplementation is required for the target group. Further research is recommended to identify the specific risk factors for ID and IDA. Finally, nutrition education and intervention program should address ID with a focus on both the dietary quantity and the quality of the micronutrient composition. All of these interventions must be monitored for effectiveness.

\section{Conclusion}

The result of the study indicates that iron supplementation is required for the target group. As the nursing students resided in hostel their hostel food should also be evaluated to find out if there is any shortfall in their dietary iron .The dietary habits of the students should also be studied to find out their intake of inhibitors and enhancer of iron absorbance just before and after meal to fully eradicate IDA and ID among them.

Acknowledgement: We would to like extend our sincere thanks to Prof Satish kumar Baburao Patil Prof and HOD Department pf Biochemistry Chattisgarh Institute of Medical Sciences,(CIMS), Principal, Govt. Nursing college Bilaspur (C.G) for her kind permission to carry out the study, we also grateful to the nursing students and technical staff of Biochemistry department CIMS, Bilaspur (C.G.).

\section{Funding: Nil \\ Conflict of interest: Nil}

Permission from IRB: Yes

\section{References}

1. Stoltzfus RJ, Dreyfuss ML. Guideline for the use of iron supplements to prevent and treat iron deficiency anemia. Washington (DC): ILSI Press, 1998.

2. Verster A. Guidelines for the control of iron deficiency in countries of the eastern Mediterranean, Middle East and North Africa. Alexandria, Egypt: World Health Organization, Regional Office for the Eastern Mediterranean 1996 (WHOEM/NUT/177/E/G/11,96)

3. Murphy MF, Waisncoat J, Colvin BT. Microcytic anemia.In: Kumar P, Klark M. Clinical medicine, 5th ed. Edinburgh, UK: W. B. Saunders, 2002; 412-19.

4. Bertil G. Iron-deficiency anemia. In: Nelson textbook of paediatrics, 17th ed. Philadelphia, PA, USA: W. B. Saunders, 2004:1614-1615.

5. Abalkhail B, Shawky S. Prevalence of daily breakfast intake, iron deficiency anaemia and awareness of being anaemic among Saudi school students. International Journal of Food Sciences and Nutrition. 2002;53(6):519-528.

6. Klaus Kraemer and Michael B. Zammermann. Nutritional Anemia, The Sight and Life, Switzerland; 2007

7. Haas J, Brownlie T. Iron Deficiency and Reduced Work Capacity: A Critical Review of the Research to Determine a Causal Relationship. J Nutr. 2001;131(Supp): 376-390. 
8. Halterman JS, Kaczorowski JM, Aligne CA, Auinger P, Szilagyi PG. Iron deficiency and cognitive achievement among school aged children and adolescents in the United States. Pediatrics. 2001 Jun;107(6):1381-6.

9. Upadhyay S, Kumar AR, Raghuvanshi RS, Singh BB. Nutritional Status and Knowledge of Hill Women on Anaemia : Effect of Various Socio-demographic Factors. J Hum Ecol 2011; 33(1): 29-34.

10. McCann J, Ames BN. An overview of evidence for a causal relation between iron deficiency during development and deficits in cognitive or behavioral function. Am. J. Clin. Nutr 2007; 85(4): 931-945.

11. Nojilana B, Norman R, Dhansay MA, et al. Estimating the burden of disease attributable to iron deficiency anaemia in South Africa in 2000. S Afr Med J. 2007 Aug;97(8 Pt 2):741-6.

12. Tolentino K, Friedman JF. An update on anemia in less developed countries. Am J Trop Med Hyg. 2007 Jul;77(1):44-51.

13. Yip R, Ramakrishnan U. Experiences and challenges in developing countries. J Nutr. 2002 Apr;132(4 Suppl):827S-30S.

14. Gleason G, Gross R, Viteri F, Yip R. Indicators and Strategies for Iron Deficiency Anemia Programs. Report of the WHO/UNICEF/UNU Consultation, Oslo, Norway; 1988.

15. B.C.Mehta.Iron deficiency amongst Nursing students.Indian J.Med.Sci ,2004; 58(9):389-390.

16. WHO/UNICEF/UNU. Iron deficiency anemia: Assessment, prevention and control a guide for programme managers. Geneva, World Health Organization, (Document WHO/NHD/01.3); 2001.
17. Verdon F, Burnand B, Stubi CL, Bonard C, Graff M, Michaud A (2003). Iron supplementation for unexplained fatigue in non-anemic women:Double blind randomised placebo controlled trial. BMJ. 2003 May 24;326(7399):1124.

18. Freire WB. Strategies of the Pan American Health Organization/World Health Organization for the control of iron deficiency in Latin America. Nutr Rev. 1997 Jun;55(6):183-8.

19. Choi JW. Does Helicobacter pylori infection relate to iron deficiency anaemia in prepubescent children under 12 years of age. Acta Paediatr. 2003 Aug;92(8):970-2.

20. Andrews NC. Disorders of iron metabolism. N. Engl. J. Med 2000; 341(26): 1986-1995.

21. Rowland TW, Kelleher JF. Iron deficiency in athletes. Insights from high school swimmers. Am. J. Dis. Child 1989; 143(2):197-200.

22. Das KVK. Nutritional anemias in India. J Assoc Physicians India. 1980 Dec;28(12):521-33.

23. Nelson R, Chawala M, Conolly P, LaPorte J. Ferritin as index of bone marrow iron stores. South Med J. 1978 Dec;71(12):1482-4.

24. Holyoake TL, Stott DJ, McKay PJ, Hendry A, MacDonald JB, Lucie NP. Use of plasma ferritin concentration to diagnose iron deficiency in elderly patients. J Clin Pathol. 1993 Sep;46(9):857-60.

25. Hallberg A, Bengtsson C, Lapidus L, Lindstedt G, Lundberg PA, Hulten L. Screening for iron deficiency: An analysis based on bone marrow examinations and serum ferritin determination in a population sample of women. Br J Haematol. 1993 Dec;85(4):787-98.

\section{How to cite this article?}

Saha J, Sarkar D. Prevalence of iron deficiency and iron deficiency anaemia among nursing students of Bilaspur Chhattisgarh . Int J Med Res Rev 2015;3(7):738-742. doi: 10.17511/ijmrr.2015.i7.139. 